\title{
Cervical Internal Carotid Artery Saccular Aneurysm Manifesting with Progressive Dysphonia
}

\section{Aneurisma sacular da artéria carótida interna cervical manifestando-se por disfonia progressiva}

\author{
Arquimedes Cavalcante Cardoso ${ }^{1}$ Marcos Alcino Soares Siqueira Marques Júnior ${ }^{2}$ \\ Marcos Alcino Soares Siqueira Marques ${ }^{3}$ Luiz Eurípedes Almondes Santana Lemos ${ }^{4}$ \\ Samuel Ricardo Batista Moura ${ }^{2}$ Amanda Mendonça Marques ${ }^{2}$ Laysa Layna Ribeiro Lima ${ }^{2}$ \\ Lívio Pereira de Macedo ${ }^{5}$
}

\footnotetext{
${ }^{1}$ Interventional Neuroradiologist, PhD at Hospital Getúlio Vargas, Teresina, PI, Brazil

2 Uninovafapi University Center, Teresina, PI, Brazil

${ }^{3}$ Neurosurgeon at Hospital Getulio Vargas, Teresina, PI, Brazil

${ }^{4}$ Medical Student at Universidade Estadual do Piauí, Teresina, PI, Brazil

${ }^{5}$ Medical Student at Faculdade Integral Diferencial (FACID),

Teresina, PI, Brazil
}

Arq Bras Neurocir 2015;34:215-219.

\begin{abstract}
Address for correspondence Marcos Alcino Soares Siqueira Marques Júnior, Rua Desembargador Manoel Castelo Branco, 1540, Ap. 1600, Jóquei, Teresina, PI, Brazil CEP: 64049-270 (e-mail: marcosalcinojr@gmail.com).
\end{abstract}

\begin{abstract}
Keywords

- Internal carotid artery

- aneurysm

- dysphonia

Resumo

Palavras-chave

- artéria carótida interna

- aneurisma

- disfonia

Aneurysm of the cervical internal carotid artery is a rare condition, which can trigger severe neurologic complications. The authors report a case of a female patient of 54 years, presenting as a progressive dysphonia, which revealed it to be an aneurysm of the extracranial portion of the internal carotid artery. Endovascular treatment was used.

Aneurisma da artéria carótida interna cervical é uma patologia infrequente, podendo desencadear severas complicações neurológicas. Os autores relatam o caso de uma paciente feminina de 54 anos, apresentando-se por disfonia progressiva, que revelou tratar-se de um aneurisma da porção extracraniana da artéria carótida interna, tendo sido empregado o tratamento endovascular.
\end{abstract}

\section{Introduction}

Aneurysms of the cervical portion of the internal carotid artery (ICA) is a rare disorder, unlike the intracranial aneurysms portion. ${ }^{1}$ It is estimated to be 0.4 to $4.0 \%$ of all peripheral aneurysms. ${ }^{2}$ Regarding etiology, such aneurysmal formations occur mainly by atherosclerosis, postoperative carotid surgery, and may also occur due to trauma. ${ }^{3}$ These

received

July 25, 2014

accepted

June 12, 2015
DOI http://dx.doi.org/

10.1055/s-0035-1560029. ISSN 0103-5355. aneurysms are manifested usually by palpable masses, but also by dysphagia, local pain, hoarseness, and neurologic changes resulting from changes of the brain flow. ${ }^{4,5}$

The diagnosis can be made by computed tomography (CT) with contrast, magnetic resonance imaging (MRI), CT angiography, and MRI angiography. However, conventional digital angiography is the test most used to confirm the diagnosis, especially when there is diagnostic doubt between 


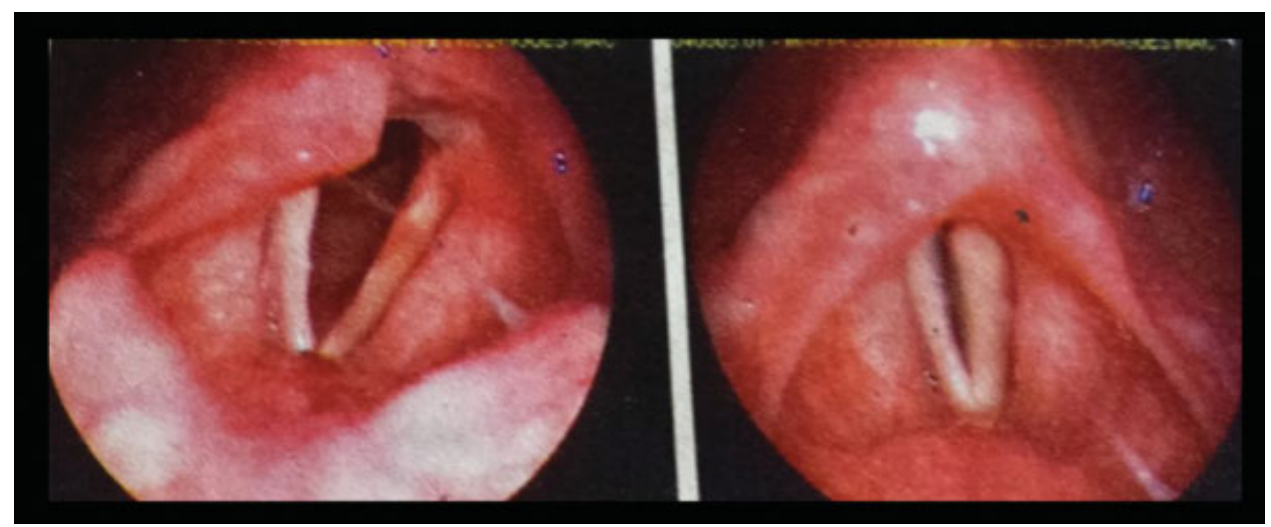

Fig. 1 Video laryngoscopy with findings of vocal cord paralysis in the right paramedian position.

aneurysm formation and glomus tumor, which is the main differential diagnosis of carotid extracranial aneurysms. ${ }^{1,6}$

The main complication of cervical carotid aneurysms is the possibility of promoting ischemic brain abnormalities due to embolism of mural thrombi occurring in 50 to $70 \%$ of cases. $^{7}$ Already bleeding, unlike intracranial aneurysms, is uncommon and can lead to death by asphyxiation due to bleeding in the oropharynx, ear canal, and soft tissues. ${ }^{8}$

This paper aims to describe a case of an aneurysm of the cervical ICA to enrich the literature on our experience facing a case of an unusual pathology.

\section{Case Report}

A 54-year-old woman, hypertensive, diabetic, and dyslipidemic, presenting with dysphonia 12 years ago and under nondrug treatment for vocal cord paralysis, was subjected to an examination of MRI of the brain. This examination showed an expansive formation on right, measuring $2.7 \times 2.4 \times 2.2 \mathrm{~cm}$ in its greatest axes, hyperintense on T2, with homogeneous contrast enhancement on T1, and adjacent to the cranial portion of the ipsilateral internal jugular vein (-Figs. 1 and 2). This mass also maintained

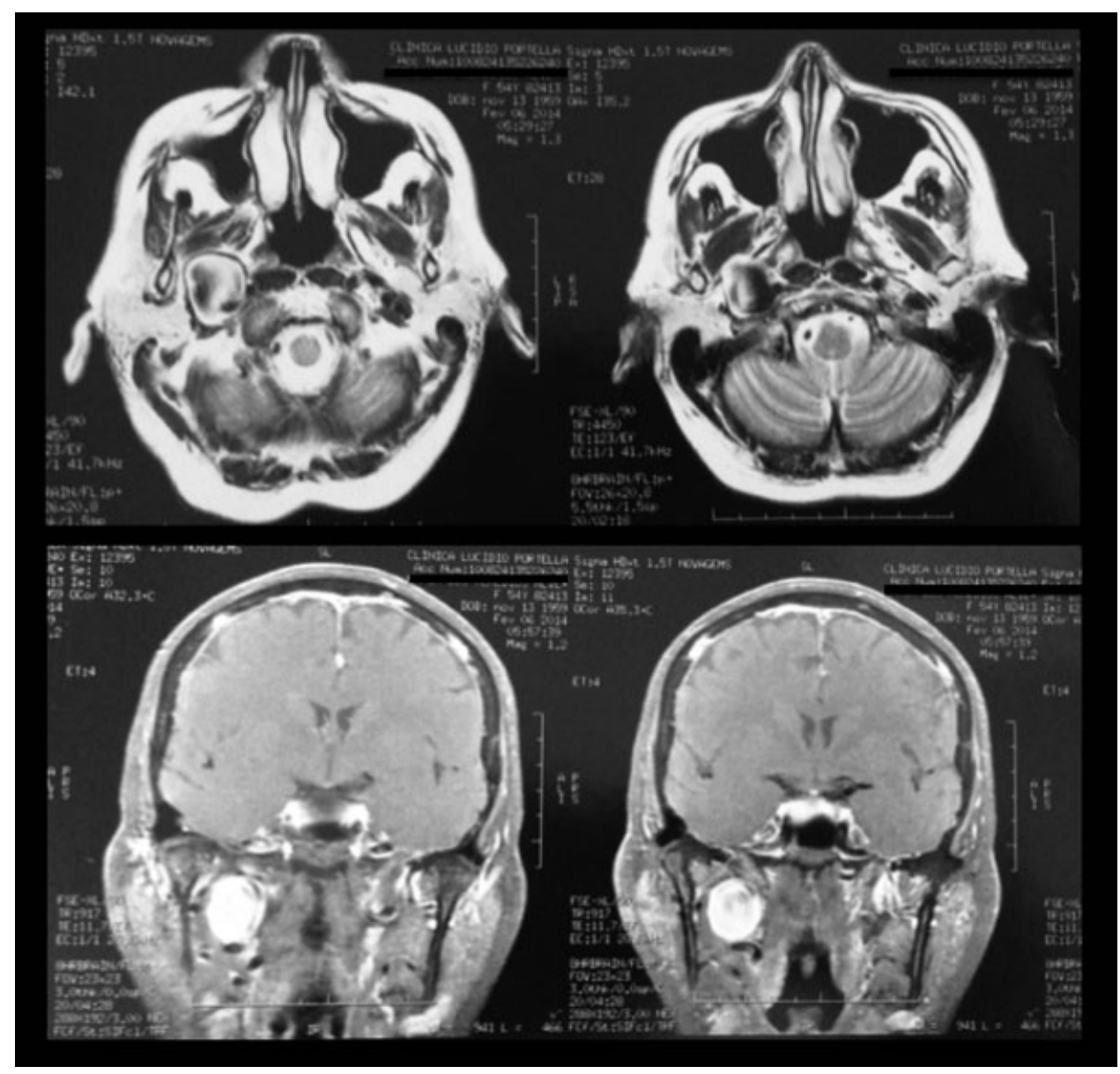

Fig. 2 MRI. The top images correspond to axial T2. Already the lower images represent the coronal postcontrast T1. 


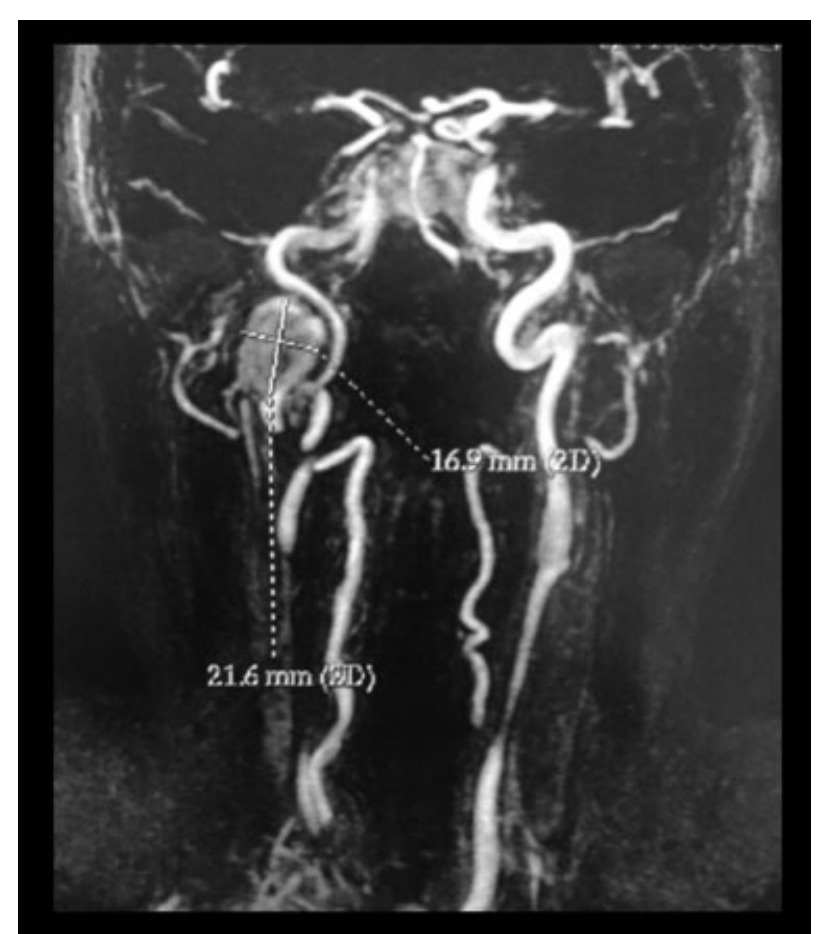

Fig. 3 Angiography MRI showing an oval-shaped formation in the right cervical internal carotid artery, considering the possibility of an aneurysm.

relationships with other ipsilateral structures: the medial pterygoid muscle and the parotid gland. Furthermore, it was promoting medial displacement of the distal portion of right cervical ICA. In this context, we considered the possibility that this was a paraganglioma. Still, we requested an MRI angiography that revealed an expansive oval image with signs of flow void in relation to the middle third of the cervical segment of the right ICA. The hypothesis of an aneurysmal formation is considered at this time (-Fig. $\mathbf{3}$ ). Then, we followed with the realization of a conventional digital angiography for diagnostic confirmation. This examination confirmed the aneurysm in the cervical segment of the right ICA, measuring $25 \times 20 \mathrm{~mm}$ in its largest diameters, not observing further signs of fibromuscular dysplasia or associated arterial dissection (-Fig. 4).

Thus, the patient was referred to the service of neurosurgery and interventional neuroradiology at the Getúlio Vargas Hospital, where she underwent for embolization of the aneurysm with coils and uneventful (-Fig. 5).

\section{Discussion}

The clinical manifestation of extracranial aneurysms of the ICA mainly occurs by a pulsatile neck mass. However, they may remain asymptomatic or manifest also by cervical discomfort, local pain, dysphagia, dysphonia, sore throat, mimicking oropharyngeal tumor, bleeding, and/or neurologic disorders. ${ }^{4,5}$ In the clinical case, the patient developed progressive dysphonia for 12 years, probably because of compression of the vagus nerve in the cervical portion, responsible for innervating the muscles of phonation, resulting in a diagnosis of vocal cord paralysis that the patient had during this period. Performing imaging studies, even if late, as in our case, is essential for avoiding diagnostic gaps. ${ }^{1,3,6}$ However, tests such as CT and MRI do not confirm the diagnosis; the fact is that blood vessel tests, such as CT angiography and MRI angiography, are needed for differentiation between aneurysms and cervical tumor. ${ }^{6}$ In our case,

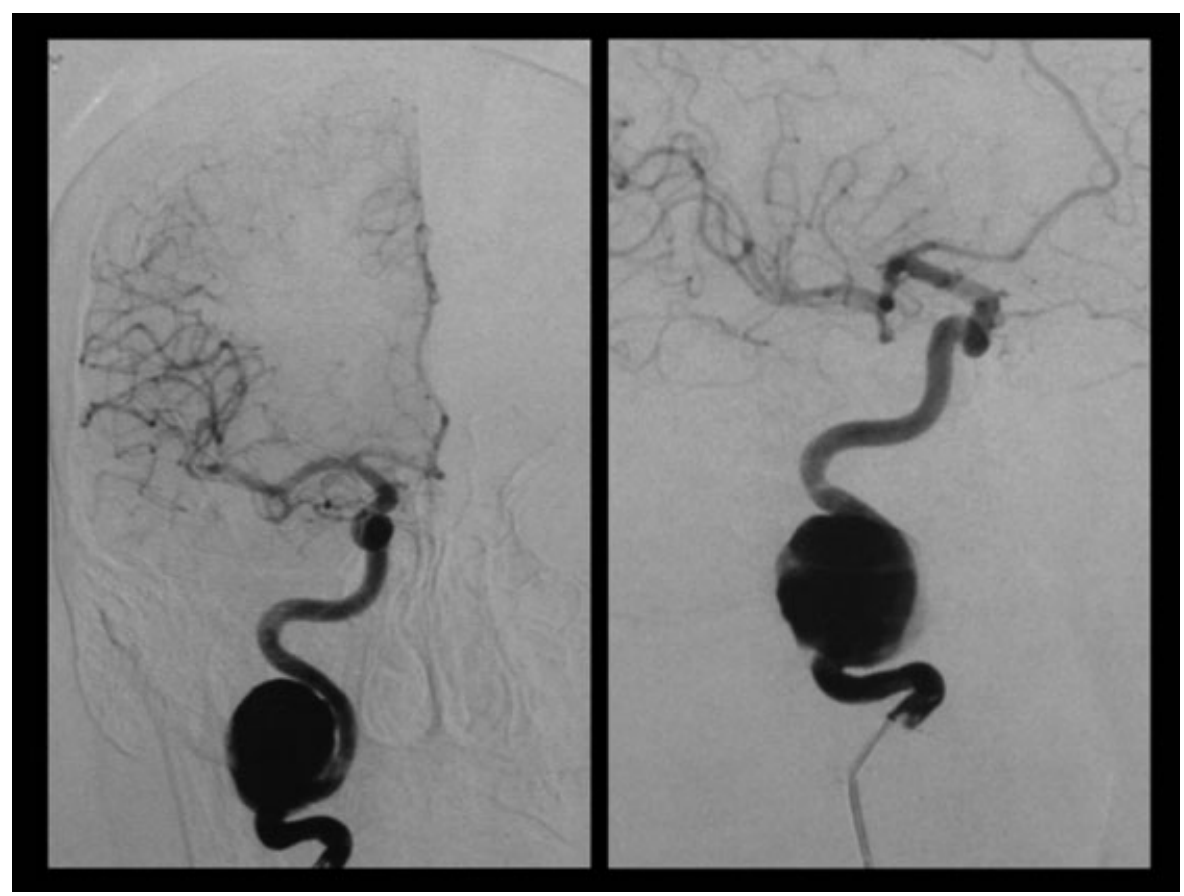

Fig. 4 Conventional digital angiography confirming the existence of saccular aneurysm in the right cervical internal carotid artery. 


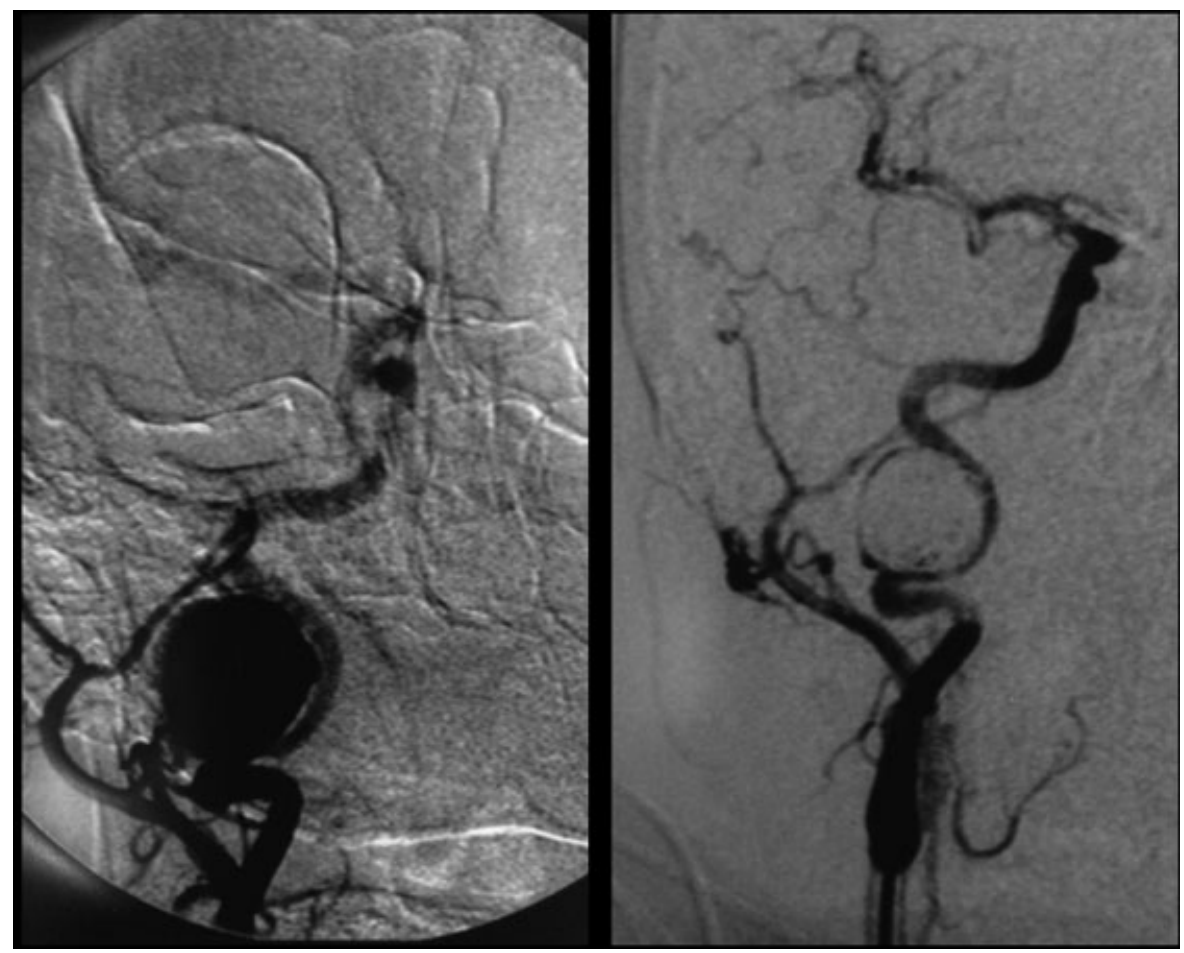

Fig. 5 Aneurysmal embolization. Before performing the procedure (on right) and after occlusion of the aneurysm with coils (on left).

the use of conventional angiography for diagnostic confirmation was necessary because there was diagnostic doubts over whether the injury was an aneurysm or a paraganglioma. Moreover, this examination is the election in cases of vascular surgery, because it allows better assessment of the injury and the vascular anatomy. ${ }^{3}$ In other cases cited in the literature, the diagnostic uncertainty remained until the intraoperative moment, even after conducting of MRI and conventional angiography. ${ }^{6}$ There are reports in the literature also about the use of ultrasound, with or without Doppler associated, with good sensitivity for identifying extracranial aneurysms of ICA.

The probable etiology for aneurysm involved in our case involves atherosclerosis, because of the patient's comorbidities (hypertension, diabetes mellitus, and dyslipidemia) as well as the lack of a history of trauma to the region and of a pattern of carotid dissection or dysplasia fibromuscular on conventional digital angiography.

As for the approach to be employed, surgical or endovascular, we chose the intraluminal pathway because of the good results of the team local interventional neuroradiology and the best immediate postoperative recovery with earlier return to daily activities of the patient. ${ }^{9,10}$ The procedure was uneventful, and the patient was discharged on the fourth postoperative day.

\section{Conclusion}

Through the analysis of this case report and literature on the subject, it is important not to ignore symptoms such as dysphonia, dysphagia, and odynophagia for an adequate investigation of the cervical pathologies, including aneur- ysms of extracranial ICA. With regard to the treatment option, endovascular treatment showed satisfactory outcome with no complications and complete embolization of the aneurysm.

\section{Conflict of Interest}

The authors declare no conflict of interest.

\section{References}

1 McCollum CH, Wheeler WG, Noon GP, DeBakey ME. Aneurysms of the extracranial carotid artery. Twenty-one years' experience. Am J Surg 1979;137(2):196-200

2 Akan H, Selçuk MB, Incesu L, Günes M, Tekat A. Aneurysm of extracranial internal carotid artery: radiologic evaluation. Turk Otol Arsivi 1997;35:111-114

3 Garcia MRT, Chammas MC, Caiado AHM, Juliano AG, Leite CC, Cerri GG. Aneurisma da artéria carótida interna extracraniana: relato de caso. Radiol Bras 2004;37(4):295-297[serial on the Internet]

4 Mokri B, Piepgras DG, Sundt TM Jr, Pearson BW. Extracranial internal carotid artery aneurysms. Mayo Clin Proc 1982;57(5): 310-321

5 Lim YM, Lee SA, Kim DK, Kim GE. Aneurysm of the extracranial internal carotid artery presenting as the syndrome of glossopharyngeal pain and syncope. J Neurol Neurosurg Psychiatry 2002; 73(1):87-88

6 Della Negra LA, Simões CA, Rossi FH, et al. Extracranial internal carotid artery aneurysm presenting as glomus tumor. Arqu Bras Ciênc Saúde 2010;35(3):231-233

7 Moraes GP, Marcondes CA, Souza MP, et al. Aneurisma Extracraniano de Artéria Carótida Interna. Rev Bras Cir Cabeça Pescoço 2007;36(2):118-120 
8 Rittenhouse EA, Radke HM, Sumner DS. Carotid artery aneurysm. Review of the literature and report of a case with rupture into the oropharynx. Arch Surg 1972;105(5):786-789

9 Szopinski P, Ciostek P, Kielar M, Myrcha P, Pleban E, Noszczyk W. A series of 15 patients with extracranial carotid artery aneurysms: surgical and endovascular treatment. Eur J Vasc Endovasc Surg 2005;29(3):256-261

10 Zhang Q, Duan ZQ, Xin SJ, Wang XW, Dong YT. Management of extracranial carotid artery aneurysms: 17 years' experience. Eur J Vasc Endovasc Surg 1999;18(2):162-165 